\title{
Prenatal androgen exposure programs metabolic dysfunction in female mice
}

\author{
Alison V Roland ${ }^{1}$, Craig S Nunemaker ${ }^{1}$, Susanna R Keller ${ }^{1,2}$ and Suzanne M Moenter ${ }^{1,2}$ \\ Departments of ${ }^{1}$ Medicine and ${ }^{2}$ Cell Biology, University of Virginia, PO Box 800578, Charlottesville, Virginia 22908, USA \\ (Correspondence should be addressed to S M Moenter; Email: smoenter@umich.edu)
}

\begin{abstract}
Polycystic ovary syndrome (PCOS) is a common fertility disorder with metabolic sequelae. Our laboratory previously characterized reproductive phenotypes in a prenatally androgenized (PNA) mouse model for PCOS. PNA mice exhibited elevated testosterone and LH levels, irregular estrous cycles, and neuroendocrine abnormalities suggesting increased central drive to the reproductive system. In this study, we examined metabolic characteristics of female PNA mice. PNA mice exhibited increased fasting glucose and impaired glucose tolerance (IGT) that were independent of age and were not associated with changes in body composition or peripheral insulin sensitivity. IGT was associated with defects in pancreatic islet function leading to
\end{abstract}

an impaired response to high glucose, consistent with impaired insulin secretion. Exposure of isolated pancreatic islets to androgen in vitro demonstrated an impaired response to glucose stimulation similar to that in PNA mice, suggesting androgens may have activational in addition to organizational effects on pancreatic islet function. PNA mice also exhibited increased size of visceral adipocytes, suggesting androgenprogramed differences in adipocyte differentiation and/or function. These studies demonstrate that in addition to causing reproductive axis abnormalities, in utero androgen exposure can induce long-term metabolic alterations in female mice.

Journal of Endocrinology (2010) 207, 213-223

\section{Introduction}

Developmental programing by steroid hormones is important to establish sex differences in the reproductive tract and in other physiological systems. Androgen levels surge during gestation and postnatally in the male (Tapanainen et al. 1981, Quigley 2002), while in females androgens typically remain low during embryonic development, except in rare instances of pathologic exposure from intrinsic (fetal) or extrinsic (maternal or environmental) sources. Recent work on endocrine disruptors has demonstrated the existence of environmental substances with androgenic actions, such as $17-\beta$-trenbolone and triclocarban, which are a potential cause of abnormal fetal androgenization (Gray et al. 2006, Hotchkiss et al. 2007, Chen et al. 2008). As hormonal perturbations during this critical time may have adverse effects that persist into adulthood, it is important to study the consequences of androgen exposure in utero.

Polycystic ovary syndrome (PCOS), the most common cause of infertility in women, is one disorder that may originate in prenatal androgen excess. PCOS is characterized by hyperandrogenemia, elevated central drive to the reproductive system, and irregular or absent menstrual cycles due to oligo- or anovulation (Dunaif 1997). PCOS also predisposes women to metabolic dysfunction characterized by impaired glucose homeostasis and abdominal adiposity (Sam \& Dunaif 2003). Animal models have exhibited reproductive and metabolic abnormalities similar to PCOS following prenatal androgenization (Abbott et al. 2005, Dumesic et al. 2007, Demissie et al. 2008). The finding that prenatal androgen can lead to defects in both reproduction and metabolism suggests it may play a major role in the etiology of at least some cases of PCOS. Consistent with this idea, women with PCOS have elevated circulating androgens during late gestation (Sir-Petermann et al. 2002), potentially exposing their offspring, who are at increased risk for PCOS (Sir-Petermann et al. 2009). Alternatively, it has been proposed that the fetal ovary itself is the source of androgen due to abnormalities in genes controlling steroidogenesis (Legro et al. 1998).

To mimic the gestational androgen excess associated with PCOS and other inappropriate androgen exposures, our laboratory developed a mouse model treated with dihydrotestosterone (DHT) late in gestation. Previously, we described reproductive neuroendocrine abnormalities in this model (Sullivan \& Moenter 2004), including elevated androgen and LH levels, irregular estrous cycles, and increased excitatory neurotransmission to GnRH neurons. In this study, we investigate metabolic phenotypes in prenatally androgenized (PNA) mice. 


\section{Materials and Methods}

\section{Generation of PNA mice}

Adult (2-4 months) female GnRH-green fluorescent protein (descended from CBB6/F1 founder, currently $\sim 75 \%$ $\mathrm{C} 57 \mathrm{Bl} / 6 \mathrm{~J}$ by speed congenics) transgenic mice were used to generate PNA mice. Mice were housed under a $14 \mathrm{~h}$ light:10 h darkness cycle with chow (2916, Harlan, Indianapolis, IN, USA) and water made available ad libitum. Females were paired with males and checked for copulatory plugs. The date of plug was considered day 1 of gestation. Pregnant mice were injected daily s.c. with $50 \mu \mathrm{l}$ sesame oil containing $250 \mu \mathrm{g}$ of DHT on days 16-18 of gestation. DHT was used to eliminate the possibility of aromatization to estradiol $\left(\mathrm{E}_{2}\right)$, thereby permitting the study of primarily androgen receptormediated effects. Of note, DHT can be metabolized to $5 \alpha$ androstane-3 $\beta, 17 \beta$-diol, which can bind estrogen receptor (ER) $\beta$ (Handa et al. 2008); however, the levels of this metabolite attained in the fetal compartment are unknown. Female offspring were subjected to glucose tolerance tests (GTTs) beginning at 1 month of age; all other studies were performed at 3-6 months. Control mice (CON) were offspring of either oil-injected dams or untreated mice; no differences were observed between these groups, and they were combined for analysis. Three rounds of PNA mice were generated for use in this study: $9 \mathrm{CON}$ and 7 PNA mice for repeated glucose tolerance testing; $22 \mathrm{CON}$ and 21 PNA mice for dual energy X-ray absorptiometry (DEXA), adipocyte studies, islet studies, and hormone measurements; and $10 \mathrm{CON}$ and 10 PNA mice for insulin tolerance testing. For in vitro examination of steroid effects on pancreatic islets, C57BL/6J female mice 8-12-weeks old were purchased from Jackson Laboratories (Bar Harbor, ME, USA). These mice were ovariectomized (OVX) 3 days before islet isolation under isoflurane anesthesia (Burns Veterinary Supply, Westbury, NY, USA). Long-acting postoperative local analgesia was provided by $0 \cdot 25 \%$ bupivacaine (Abbott Laboratories). All procedures were approved by the University of Virginia Animal Care and Use Committee and conducted in accordance with the National Research Council's Guide for the Care and Use of Laboratory Animals.

\section{Glucose tolerance tests}

Mice were singly housed on Sani-Chip bedding (Harlan) and fasted overnight for $16 \mathrm{~h}(1600-0800 \mathrm{~h})$ prior to the test. The tail was anesthetized with the skin refrigerant ethyl chloride (Gebauer, Cleveland, OH, USA) and the tip removed with a sterile scalpel blade. Tail blood $(\sim 1 \mu \mathrm{l} / \mathrm{sample})$ was collected for glucose measurement with a OneTouch Ultra glucometer (Lifescan, Milpitas, CA, USA). Following a fasting glucose measurement, mice were injected i.p. with a bolus of $1 \mathrm{~g} / \mathrm{kg}$ glucose in $0.9 \% \mathrm{NaCl}$. Blood glucose was assessed at 10, 20, $30,45,60,75,90$, and $120 \mathrm{~min}$ post injection. GTTs were performed monthly from 1 to 6 months.

\section{Insulin tolerance tests}

Studies were performed $10 \mathrm{~h}$ after lights-on in singly housed fed mice. Although mice had free access to food prior to testing, their active (feeding) period normally ends at the time of lights-on. Following an initial glucose measurement, mice were injected i.p. with a bolus of $0.75 \mathrm{U} / \mathrm{kg}$ insulin in sterile $0.9 \% \mathrm{NaCl}$. Blood glucose was determined at 10, 20, 30, 45, 60 , and 75 min post injection as described above.

\section{Fasting insulin measurements}

Fasting insulin was measured following an overnight fast (1600-0800 h). Five- to six-month-old mice were restrained, and $\sim 50 \mu \mathrm{l}$ blood was collected from the tail vein using a heparinized capillary tube. Plasma insulin was determined by radioimmunoassay (Millipore, Billerica, MA, USA, cat\# SRI-13K). All samples were determined in a single assay with a sensitivity of $0.1 \mathrm{ng} / \mathrm{ml}$ and intra-assay coefficient of variation $(\mathrm{CV})$ of $<10 \%$.

\section{Dual energy X-ray absorptiometry}

Mice were anesthetized by i.p. injection of $100-150 \mu \mathrm{l}$ of a ketamine/xylazine mix in saline (ketamine at $20 \mathrm{mg} / \mathrm{ml}$ and xylazine at $2 \mathrm{mg} / \mathrm{ml}$ ). Anesthetized mice were introduced into the DEXA machine (GE Lunar Piximus II, GE Healthcare, Waukesha, WI, USA) and were subjected to total body imaging. Lean body mass and fat mass were determined using the Lunar Piximus II software and percent fat mass was calculated. Abdominal fat percentage was calculated by selecting a region of interest in the scanned image. Mice were scanned at age 3, 4, and 5 months.

\section{Measurement of adipocyte size}

Mice were euthanized with $\mathrm{CO}_{2}$. The left parametrial fat pad and the adjacent uterus were fixed in 10\% formalin for $48 \mathrm{~h}$ and embedded in paraffin. Sections $(5 \mu \mathrm{m})$ were cut and stained with hematoxylin-eosin. Pictures of stained sections were taken at $\times 10$ magnification with a Zeiss Axioplan Universal Microscope (Thornwood, NY, USA); the uterus was used for photographic orientation and the adipocytes sized were in the same frame as the uterus to minimize bias due to regional differences. Cell areas (in $\mu \mathrm{m}^{2}$ ) of 50 adipocytes were determined for each mouse using Scion Image Corporation software (Frederick, MD, USA). Only 40 cells were used for one animal in which tissue damage precluded analysis of 50 cells.

\section{Glucose uptake assays in adipocytes}

The right parametrial adipose tissues were dissected, and adipocytes were isolated and subjected to glucose uptake assays as previously described in detail (Liu et al. 1999). In brief, isolated adipocytes were pre-incubated without (basal) or with different concentrations of insulin $(0-10 \mathrm{nM})$ for $30 \mathrm{~min}$. 
$\left[\mathrm{U}_{-}{ }^{14} \mathrm{C}\right]$ D-glucose was then added. Thirty minutes after the addition of radiolabeled glucose, the cell suspension was harvested and adipocytes were separated from the medium. Cell-associated radioactivity was determined and glucose uptake was expressed in amol/min per cell. Cell numbers were determined (Rosenbaum et al. 1993) by measuring lipid content of aliquots of cell suspension and measuring sizes of the adipocytes in aliquots of the cell suspension as described above. For each condition, the measurements were done in quadruplicate.

\section{Islet isolation}

Islets were harvested from 5-month-old PNA and CON mice on diestrus (determined by vaginal lavage). Noncycling animals are likely to have a very different steroid milieu despite similar vaginal cytology, this is a consequence of the considerable reproductive disruption of the model, and diestrous versus long-term diestrous animals is the most practical comparison to make. Mice were killed with $\mathrm{CO}_{2}$ and cardiac puncture was performed for blood collection. The pancreas was dissected and islets were isolated by collagenase digestion and Histopaque centrifugation using previously detailed methods (Carter et al. 2009). Isolated islets were transferred to a Petri dish containing standard RPMI 1640 (Invitrogen) with 10\% fetal bovine serum and penicillin/ streptomycin. Islets were incubated in this medium overnight to allow recovery from digestion prior to experiments.

\section{Intracellular calcium imaging of islets}

The day following isolation, imaging recordings of intracellular calcium $\left(\left[\mathrm{Ca}^{2+}\right]_{\mathrm{i}}\right.$ ) were made from groups of $10-20$ islets from a single mouse $\sim 18-26 \mathrm{~h}$ post isolation; no differences were noted based on time of recording. $\left[\mathrm{Ca}^{2+}\right]_{i}$ was measured using the ratiometric dye fura-2 AM and previously described methods (Jahanshahi et al. 2009). Briefly, islets were incubated with $1 \mu \mathrm{M}$ fura-2 AM for $30 \mathrm{~min}$ in a modified Kreb's ringer buffer (KRB) solution containing $3 \mathrm{mM}$ glucose, washed, then transferred to a small volume chamber (Warner Instruments, Hamden, CT, USA) mounted on the stage of an upright Olympus BX51WI fluorescence microscope (Olympus, Tokyo, Japan). Islets were perifused using a peristaltic pump (Minipuls 2, Gilson, Middleton, WI, USA) and maintained at $35^{\circ} \mathrm{C}$ with an in-line heater (model SF-28 with automatic temperature controller model TC324B, Warner Instruments). A Hamamatsu ORCA-ER camera (Hamamatsu Photonics, Hamamatsu City, Japan) was used to take sequential images during 340 and $380 \mathrm{~nm}$ excitation, and the ratio of emitted light at $510 \mathrm{~nm}$ was used to determine the $\left[\mathrm{Ca}^{2+}\right]_{\mathrm{i}}$. Excitation from a xenon burner was accomplished using a light pipe and filter wheel (Sutter Instrument Company, Novato, CA, USA). Paired images were recorded every $5 \mathrm{~s}$ for $15 \mathrm{~min}$. After $5 \mathrm{~min}$ in $3 \mathrm{mM}$ glucose, $11 \mathrm{mM}$ glucose was applied for $10 \mathrm{~min}$, during which fluorescence levels were recorded continuously.

\section{Insulin release in vitro}

A subset of islets isolated from PNA and CON mice were used for studies of in vitro insulin release. Following the overnight culture, islets were incubated at $37{ }^{\circ} \mathrm{C}$ and $5 \% \mathrm{CO}_{2}$ for $1 \mathrm{~h}$ in standard KRB solution. Islets were then washed and treated for $1 \mathrm{~h}$ in KRB supplemented with $3 \mathrm{mM}$ glucose, followed by $1 \mathrm{~h}$ in KRB containing $11 \mathrm{mM}$ glucose. Supernatants were collected after each treatment. Insulin concentration in the supernatant was measured by an ELISA insulin assay kit (Mercodia Inc., Winston Salem, NC, USA) according to manufacturer instructions. This assay differed from that used for mouse serum because insulin levels in media differ from those in vivo. Intra-assay variation was $<10 \%$ and inter-assay variation was $<5 \%$. In vitro insulin release was also assessed in islets isolated from 3-month-old female C57BL/6J mice 3 days post ovariectomy. Islets were harvested and cultured as described above. During the overnight culture, 50 islets per mouse were incubated in DHT, DHT $+E_{2}$, or ethanol vehicle (0.0001\%). All steroids were used at a final concentration of $10 \mathrm{nM}$. The following day, islets from each steroid treatment group were incubated in standard KRB solution with steroids omitted to preclude acute effects. Insulin release in 3 and $11 \mathrm{mM}$ glucose was quantified by ELISA as described above.

\section{Endocrine measures}

Testosterone was measured in serum using an RIA kit according to the manufacturer's instructions (Siemens Medical Solutions, cat\# TKTT2, Los Angeles, CA, USA). Sensitivity averaged $10 \mathrm{ng} / \mathrm{dl}$, and the intra- and inter-assay CV values were $4 \cdot 4$ and $8 \cdot 1 \%$ respectively. An adipokine panel was used to assess insulin, leptin, interleukin 6 (IL6), tumor necrosis factor $\alpha(\mathrm{TNF} \alpha)$, plasminogen activator inhibitor 1 (PAI-1; also known as Serpine1), and resistin (mouse serum adipokine kit, Millipore, cat\# MADPK-71K07). Sensitivity was $12 \mathrm{pg} / \mathrm{ml}$ for insulin, leptin, PAI-1, and resistin, $2 \mathrm{pg} / \mathrm{ml}$ for $\mathrm{TNF} \alpha$, and $5 \mathrm{pg} / \mathrm{ml}$ for IL6. Intra- and inter-assay $\mathrm{CV}$ values were $<10 \%$ for all analytes. Adiponectin was measured via RIA (Millipore, cat\# MADP-60K); assay sensitivity was $1.3 \mathrm{ng} / \mathrm{ml}$ and inter- and intra-assay CV values were $<9$ and $<5 \%$ respectively.

\section{Estrous cycle monitoring}

Estrous cycles were monitored by vaginal lavage. Cycle stage was classified as estrus (primarily cornified cells), diestrus (primarily leukocytes), or proestrus (primarily nucleated cells).

\section{Statistical analysis}

GraphPad Prism software (La Jolla, CA, USA) was used for all analyses unless otherwise indicated. For GTT and insulin tolerance test (ITT), glucose values from PNA and CON mice were compared at each time point using a two-tailed Student's 
$t$-test. Area under the curve (AUC) for the GTTwas calculated using Igor Pro software (Wavemetrics, Lake Oswego, OR, USA); AUC across age was compared in PNA versus CON mice using a repeated-measures ANOVA and Fisher's protected least significant differences post hoc test. Two-tailed Student's t-test or Mann-Whitney test was used to compare body mass and fat pad mass, fat percentages, fat cell sizes, adipokines, HOMA indices, and glucose uptake in adipocytes. For islet calcium imaging studies, calcium measurements from 10-20 islets per mouse were averaged, and AUC was calculated using Igor Pro. Insulin secretion in 3 and $11 \mathrm{mM}$ glucose from control, DHT, and DHT $+\mathrm{E}_{2}$ groups was compared by two-way ANOVA. For all statistical tests, significance was set at $P<0 \cdot 05$. Parametric or nonparametric comparisons were used as dictated by data distribution.

\section{Results}

PNA mice do not have altered body composition but do have enlarged visceral adipocytes

As adiposity contributes to metabolic disease, we assessed body mass and composition in PNA $(n=8)$ and CON $(n=9)$ mice. Body mass at age 3, 4, and 5 months did not differ between groups (all comparisons at $P>0 \cdot 8$ ); representative data from age 5 months are shown (Fig. 1A). Body fat percentages as measured by DEXA also showed no difference in total body fat or abdominal fat at these ages $(P>0 \cdot 4$, Fig. 1B). Since DEXA cannot differentiate visceral and subcutaneous fat compartments, we could not exclude the possibility that PNA mice have changes in fat distribution. To better assess visceral adiposity, parametrial fat pads were weighed in a subsequent group of PNA mice and further analyzed for adipocyte size. Fat pad weights were similar $(n=8 \mathrm{CON}, n=11$ PNA, $P>0 \cdot 5$, Fig. $2 \mathrm{~A})$, indicating no increase in visceral adiposity in PNA mice, consistent with the DEXA measurements. However, PNA mice had larger visceral adipocytes $\left(2592 \pm 150 \mu^{2}\right.$ CON,$n=10$, $3230 \pm 211 \mu \mathrm{m}^{2}$ PNA, $n=12, P<0 \cdot 05$, Fig. $\left.2 \mathrm{~B}-\mathrm{D}\right)$, indicating that despite similar total amounts of parametrial fat in these mice, prenatal androgenization induced changes in adipocyte differentiation and/or function leading to larger fat cells. Adipokine assays showed no differences between PNA and $\mathrm{CON}$ mice in the fed or fasted state, except for a strong trend (two-tailed $P=0 \cdot 08$ ) for reduced adiponectin in fed PNA mice (Table 1). Fasting decreased insulin, leptin, PAI-1, IL6, and resistin in CON mice $(P<0 \cdot 05)$. In PNA mice, insulin was reduced and IL6 and resistin showed a tendency $(P<0.06)$ to be lower in fasted animals. Of note, however, leptin was not reduced by fasting in PNA mice. Glucose uptake assays in isolated adipocytes showed no change in insulin sensitivity or maximal insulin-stimulated glucose uptake, but higher basal glucose uptake in PNA adipocytes (basal: $4 \cdot 0 \pm 0 \cdot 5 \mathrm{amol} / \mathrm{glc}$ per min per cell $\mathrm{CON}, 6 \cdot 4 \pm 1 \cdot 0$ PNA, $n=5$ each, $P<0 \cdot 05$; at $0 \cdot 1 \mathrm{nM}$ insulin: $17 \cdot 4 \pm 2 \cdot 4$
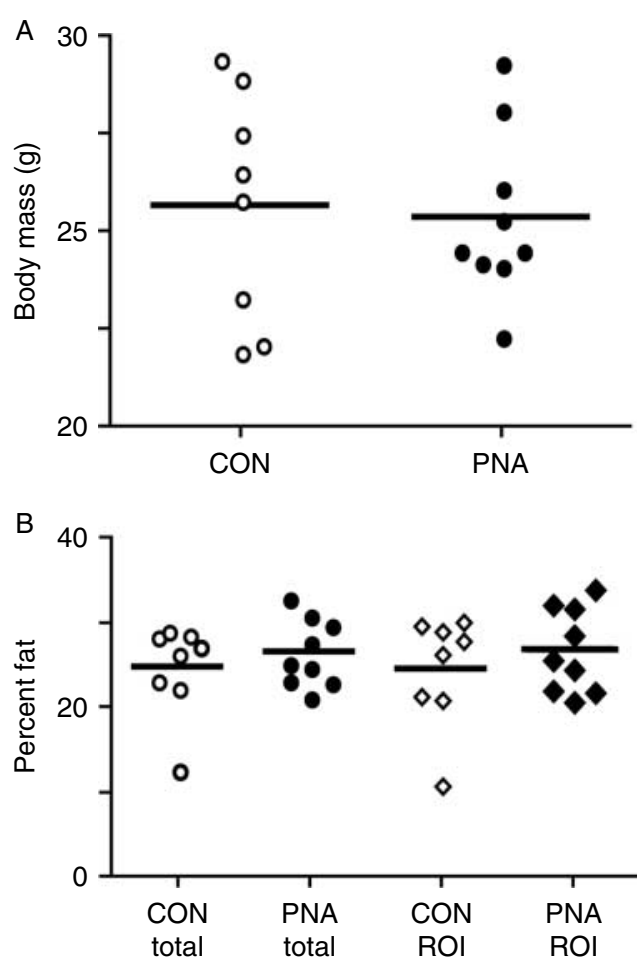

Figure 1 PNA does not alter body mass or composition in PNA mice at 5 months of age. (A) Body mass in CON (open circles, $n=8$ ) and PNA mice (closed circles, $n=9)(P>0 \cdot 8)$. (B) Total body fat or abdominal fat (region of interest, $\mathrm{ROI}$; subcutaneous and visceral fat combined) in CON and PNA $(P>0 \cdot 4)$.

CON, $20 \cdot 6 \pm 3 \cdot 3$ PNA, $n=5$ each, $P>0 \cdot 4$; at $1 \mathrm{nM}$ insulin: $27 \cdot 1 \pm 3 \cdot 3$ CON, $n=5,26 \cdot 9 \pm 5 \cdot 7$ PNA, $n=4$, $P>0 \cdot 9$; Fig. 2E).

\section{PNA mice exhibit impaired glucose tolerance}

To test whether prenatal androgenization alters glucose disposal in PNA mice, GTTs were performed. PNA mice exhibited impaired glucose tolerance (IGT) at all ages studied, with the exception of 2 months, when glucose tolerance transiently worsened in controls $(n=9 \mathrm{CON}, n=7$ PNA, $P<0 \cdot 05$ at age $1,3-6$ months at $45-120$ min time points). Figure $3 \mathrm{~A}$ shows representative average glucose curves at age 5 months; Fig. 3B shows the average area under the glucose curve at each age studied (repeated-measures ANOVA, $P<0 \cdot 05)$. Fasting glucose was significantly higher in PNA mice (glucose: CON $68 \cdot 7 \pm 4 \cdot 2 \mathrm{mg} / \mathrm{dl}, n=9$, PNA 86.7 $\pm 4.9 \mathrm{mg} / \mathrm{dl}, n=7, P<0 \cdot 02)$.

\section{PNA mice exhibit normal peripheral insulin sensitivity}

Glucose intolerance occurs due to the failure of insulin target tissues to adequately dispose of circulating glucose. This can be a consequence of impaired insulin secretion and/or impaired insulin action. To assess the latter, we performed 

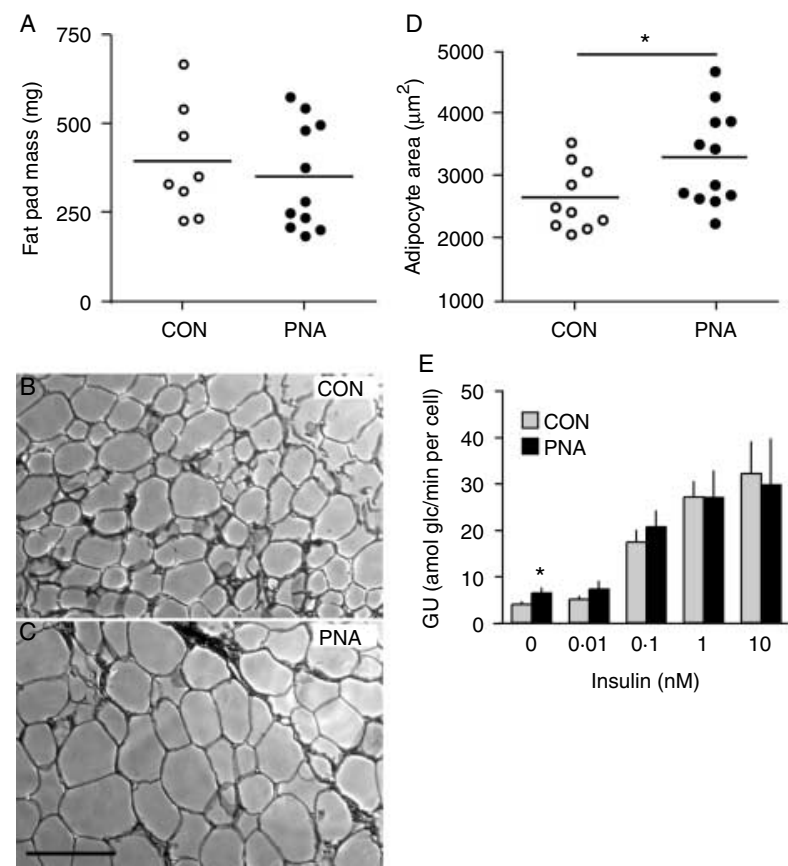

Figure 2 PNA does not alter fat pad mass but increases adipocyte size. (A) Fat pad mass in CON (open circles) and PNA mice (closed circles) ( $n=8 \mathrm{CON}, n=11 \mathrm{PNA}, P>0 \cdot 5)$. (B and C) Representative photomicrographs of adipose tissue from control (CON) (B) and PNA (C) mice. Scale bar represents $200 \mu$ M. (D) Mean adipocyte size ( $n=10 \mathrm{CON}, n=12 \mathrm{PNA})$. (E) Mean \pm s.E.M. glucose uptake (GU) into CON (gray bars) and PNA (black bars) adipocytes in response to varying concentrations of insulin $(n=2-5$ assays per insulin concentration). Basal uptake was higher in PNA adipocytes, but insulin sensitivity was similar. ${ }^{*} P<0 \cdot 05$.

an ITT in a group of 3-month-old mice. No differences were found between PNA and CON mice $(n=10$ per group, all comparisons at $P>0 \cdot 2$, Fig. 3C). Fed basal glucose levels were also not different (CON 164.8 $\pm 11 \cdot 8 \mathrm{mg} / \mathrm{dl}$, PNA $162 \cdot 7$ $\pm 10 \cdot 1 \mathrm{mg} / \mathrm{dl}, \quad n=10$ per group, $P>0 \cdot 8$ ). Additionally, fasting insulin and glucose values were used to determine homeostasis model assessment of insulin resistance (HOMA-IR) as a surrogate measure of insulin resistance.
This index was developed using human data but subsequently has been validated in rodents (Cacho et al. 2008, Mather 2009). No difference was found between groups $(0 \cdot 78 \pm 0 \cdot 10$ CON versus $0 \cdot 86 \pm 0 \cdot 18$ PNA, $P>0 \cdot 6$ ).

\section{PNA mice have an early form of islet dysfunction}

The presence of apparently normal insulin sensitivity in PNA mice suggested glucose intolerance might have originated in an insulin secretion defect at the level of the pancreatic $\beta$ cell. To assess pancreatic islet function, we used the ratiometric fluorescent probe fura-2 AM to measure glucose-stimulated calcium (GSCa) in islets from PNA and CON mice. GSCa is a measure of islet glucose sensitivity that allows high frequency sampling, which captures the dynamics of the biphasic response (Jahanshahi et al. 2009) and approximates that of glucose-stimulated insulin secretion (Henquin et al. 2006). $\left[\mathrm{Ca}^{2+}\right]_{\mathrm{i}}$ was monitored in islets during perifusion with $3 \mathrm{mM}$ glucose and following a switch to $11 \mathrm{mM}$ glucose. Islets from PNA $(n=6)$ and CON $(n=8)$ mice had similar calcium levels in $3 \mathrm{mM}$ glucose $(P>0 \cdot 4)$, but the rise in intracellular calcium following a switch to $11 \mathrm{mM}$ glucose was blunted in islets from PNA mice $(P<0 \cdot 05$, Fig. 4$)$.

The limited number of islets precluded performing parallel insulin secretion studies in islets from all mice. Insulin secretion was measured in islets from two mice per group. While this sample size was insufficient to perform statistical comparisons, there was good agreement between calcium responses and insulin release in high glucose, consistent with observations in the literature (Deering et al. 2009, Evans-Molina et al. 2009) (3 mM: CON 2.1 $\pm 0 \cdot 06 \mathrm{pg} / \mathrm{ml}$, PNA $5 \cdot 7 \pm 1 \cdot 5 \mathrm{pg} / \mathrm{ml} ; 11 \mathrm{mM}: \mathrm{CON} 33 \cdot 0 \pm 2 \cdot 1 \mathrm{pg} / \mathrm{ml}$, PNA $20 \cdot 8 \pm 4 \cdot 2 \mathrm{pg} / \mathrm{ml})$.

\section{Insulin release from isolated islets}

Steroids can exert organizational effects, which are mediated by developmental programing and persist in the absence of hormone, as well as activational effects, which require the immediate presence of hormone (Arnold \& Breedlove 1985). To probe the activational role of androgens in adult islet

Table 1 Adipokine levels in plasma from control (CON) and prenatally androgenized (PNA) mice under fed and fasted conditions ( $n=10-16$ per group)

\begin{tabular}{|c|c|c|c|c|}
\hline & CON fed & PNA fed & CON fasted & PNA fasted \\
\hline \multicolumn{5}{|l|}{ Analyte } \\
\hline Insulin (pg/ml) & $1071 \pm 178^{*}$ & $1331 \pm 306^{*}$ & $146 \pm 22 \cdot 5$ & $107 \pm 16 \cdot 5$ \\
\hline Leptin (pg/ml) & $2476 \pm 350^{*}$ & $1849 \pm 435$ & $926 \pm 192$ & $1468 \pm 366$ \\
\hline $\mathrm{TNF} \alpha(\mathrm{pg} / \mathrm{ml})$ & $4 \cdot 7 \pm 0 \cdot 4$ & $5 \cdot 3 \pm 0 \cdot 5$ & $6 \cdot 4 \pm 2 \cdot 0$ & $4 \cdot 1 \pm 0 \cdot 5$ \\
\hline PAl-1 (pg/ml) & $8361 \pm 1049^{*}$ & $6858 \pm 1377$ & $3635 \pm 635$ & $4246 \pm 664$ \\
\hline IL6 (pg/ml) & $17 \cdot 7 \pm 2 \cdot 2^{*}$ & $24 \cdot 6 \pm 5 \cdot 4^{\dagger}$ & $9 \cdot 2 \pm 1 \cdot 7$ & $5 \cdot 3 \pm 0 \cdot 8$ \\
\hline Resistin (pg/ml) & $1758 \pm 160 *$ & $1497 \pm 144^{+}$ & $891 \pm 95$ & $1073 \pm 159$ \\
\hline Adiponectin $(\mathrm{mg} / \mathrm{ml})$ & $16 \cdot 2 \pm 0 \cdot 7^{\ddagger}$ & $14 \cdot 0 \pm 1 \cdot 0$ & - & - \\
\hline
\end{tabular}

${ }^{*} P<0.05$ versus fasted. ${ }^{\dagger} P<0.06$ versus fasted. ${ }^{\ddagger} P=0 \cdot 08$ versus PNA. 

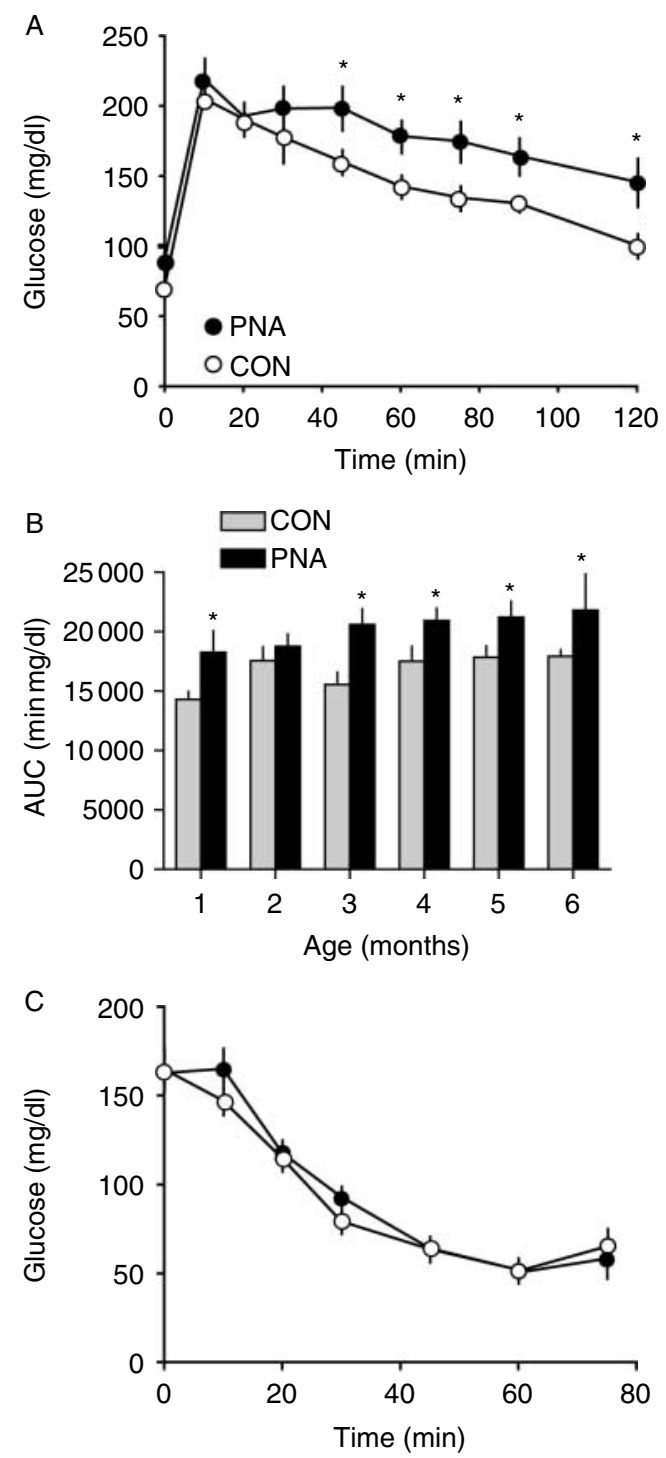

Figure 3 PNA mice exhibit impaired glucose tolerance but not insulin resistance. (A) Glucose tolerance was impaired in 5-monthold PNA (closed circles) compared to CON (open circles) mice. (B) Area under the curve (AUC) in CON (gray bars) and PNA (black bars) mice examined at different ages illustrates that glucose intolerance develops by 1 month of age. (C) PNA mice are not insulin resistant, based on insulin tolerance testing $(n=10$ per group, $P>0 \cdot 2) .{ }^{*} P<0 \cdot 05$

function, we performed an in vitro study of islet insulin secretion after incubation with different steroids. Pancreatic islets express steroid receptors, including receptors for androgen (Winborn et al. 1987, Díaz-Sánchez et al. 1995), but few studies have examined the direct roles of androgens in the islet. Islets were harvested from OVX mice 3 days post surgery. OVX mice were used to control for effects of intrinsic steroids and estrous cycles. Isolated islets were incubated overnight in $10 \mathrm{nM} \mathrm{DHT}, \mathrm{DHT}+\mathrm{E}_{2}$, or ethanol vehicle. Insulin secretion was measured in 3 and $11 \mathrm{mM}$ glucose.
Neither DHT nor the combination of $\mathrm{DHT}+\mathrm{E}_{2}$ had an effect on insulin secretion in $3 \mathrm{mM}$ glucose $(P>0 \cdot 05, n=12$ per group, Fig. 5). However, DHT and the combination of $\mathrm{DHT}+\mathrm{E}_{2}$ significantly inhibited insulin secretion in $11 \mathrm{mM}$ glucose $(P<0.01$ and $P<0.05$ respectively). This blunting of the islet response to high glucose was similar to that observed in PNA mice.

\section{Reproductive measures}

The lack of a difference in glucose tolerance at 2 months was due to an increase in glucose levels in CON mice $(P<0 \cdot 05$ by paired $t$-test), rather than an improvement in glucose tolerance in PNA mice. Interestingly, 2 months is around the age of final sexual maturation in mice (Gore et al. 1999). Given that puberty is a period of relative insulin resistance (Amiel et al. 1986), we speculated that the increase in glucose levels in CON mice may be due to pubertal changes, and PNA mice may have experienced puberty earlier or later than CON mice. To address this question, vaginal opening was monitored in a subsequent group of mice and found to occur earlier in PNA mice (CON 34.4 $\pm 1 \cdot 3$ days, $n=18$, PNA $29 \cdot 5 \pm 1.7$ days, $n=16, P<0 \cdot 05)$. Body mass at the time of vaginal opening was significantly lower in PNA mice (CON 14.9 $\pm 0.3 \mathrm{~g}$, PNA 12.7 $\pm 0.5 \mathrm{~g}, P<0.001$ ), suggesting that increased body mass was not the cause of early vaginal opening.

Serum testosterone was assayed in blood samples taken at euthanasia on the day of islet harvest. In contrast to our previous report (Sullivan \& Moenter 2004), PNA mice in this study did not exhibit elevated testosterone levels at 5 months of age (CON $10.5 \pm 3.6 \mathrm{ng} / \mathrm{dl}, n=9$, PNA $11 \cdot 9 \pm 3.0 \mathrm{ng} / \mathrm{dl}$, $n=8, P>0 \cdot 7)$. However, testosterone levels measured in a different group of mice from this cohort of PNA animals at 8 months of age revealed significantly higher levels than CON mice (CON 17.7 $\pm 2 \cdot 7 \mathrm{ng} / \mathrm{dl}, n=7$, PNA $28 \cdot 9 \pm 1.9 \mathrm{ng} / \mathrm{dl}$, $n=5, \quad P<0 \cdot 01)$. Thus, as the mice continue to age, differences in androgen levels may become apparent. In this report, metabolic studies were performed up to age 6 months.

Despite the absence of elevated testosterone, the primary reproductive phenotype of disrupted estrous cycles was apparent in PNA compared to CON mice. Cycle duration, defined as the estrus-to-estrus interval, was significantly lengthened $(6 \cdot 6+0 \cdot 4$ days $\mathrm{CON}, 15 \cdot 7+2 \cdot 6$ days PNA, $n=10$ each, $P=0.002)$ with the percent of time in estrus significantly decreased $(15 \cdot 2+1 \cdot 6 \% \mathrm{CON}, 4 \cdot 8+1 \cdot 6 \%$ PNA, $P=0 \cdot 0002)$. PNA mice exhibited prolonged periods in which leukocytes were the primary cell in the vaginal lavage. This finding differs somewhat from the original report of this model, in which similar disruptions were observed in cyclicity but prolonged periods of cornified cells were observed. We believe the difference may be attributed to a switch from phytoestrogen-containing to reduced-phytoestrogen chow. The observations of cyclicity for the three rounds of prenatal androgenization used for this study, as well as ongoing studies in the laboratory, are consistent with prolonged diestrus. 
A

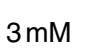

$11 \mathrm{mM}$

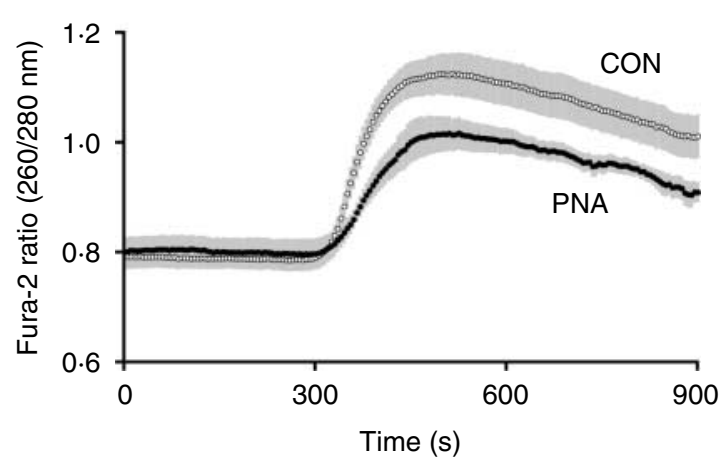

B

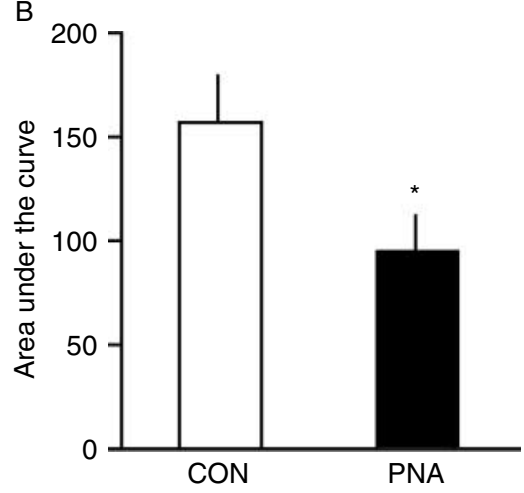

Figure 4 PNA mice have impaired pancreatic response to elevated glucose. (A) Mean \pm S.E.M. ratios ( $n=8 \mathrm{CON}, n=6$ PNA) of fura- 2 fluorescence at 260 and $280 \mathrm{~nm}$ excitation, demonstrating the impaired response of islets from PNA mice on an increase in glucose concentration from 3 to $11 \mathrm{mM}$. Shaded area indicates S.E.M. (B) Area under the curve was lower in PNA mice. ${ }^{*} P<0 \cdot 05$.

\section{PNA mice exhibit normal birth weight}

Some of the metabolic effects observed in this model coincide with those induced by intrauterine growth restriction, which has been demonstrated in sheep PNA with testosterone (Steckler et al. 2005). Birth weight was assessed in subsequent litters of PNA mice but was not altered by prenatal treatment $(\mathrm{CON} 1 \cdot 4 \pm 0 \cdot 03 \mathrm{~g}, n=33$, PNA $1 \cdot 4$ $\pm 0.03 \mathrm{~g}, n=29, P>0 \cdot 7)$.

\section{Discussion}

Prenatal androgenization of female mammals has profound lasting effects on reproductive function in adulthood, and may underlie the fertility and metabolic disorder PCOS. In this study, we assessed whether the same prenatal DHT treatment that caused reproductive abnormalities in female mice (Sullivan \& Moenter 2004) could also induce metabolic dysfunction. PNA mice exhibited glucose intolerance that was present before puberty and persisted into adulthood. IGT was not associated with increased adiposity or peripheral insulin resistance; however, pancreatic islet function was altered in PNA mice and may be a causative factor in glucose intolerance.

Glucose tolerance was studied across postnatal development since increasing adiposity with age, or changes in circulating hormones following puberty, might influence the phenotype. Of interest, PNA mice exhibited glucose intolerance at the earliest age studied, 4 weeks, and the difference relative to controls remained stable throughout the study, except at the 2 -month time point. A difference in the timing of puberty may account for the disparity at 2 months. PNA mice underwent vaginal opening earlier than $\mathrm{CON}$ mice; thus, we may have missed the window of pubertal insulin resistance in this group. Alternatively, the already impaired glucose handling in PNA mice may have masked the effects of pubertal insulin resistance. The finding of earlier puberty in PNA mice is supported by work in sheep showing pubertal advancement following prenatal androgen exposure in females (Wood et al. 1991, Jackson et al. 2008), and recent studies implicating androgens in the timing of puberty (Brill \& Moenter 2009). Further, the observation of IGT in PNA mice at only 1 month of age corresponds with the appearance of some aspects of PCOS in adolescents (McCartney et al. 2006).

PNA mice exhibited elevated fasting glucose levels in the presence of normal fasting insulin. Impaired fasting glucose is associated with hepatic insulin resistance (Bock et al. 2007), which is characterized by a failure of insulin to suppress gluconeogenesis under fasting conditions. Typically, insulin would also be elevated in this situation, but this assumes normal pancreatic $\beta$ cell compensation. Another possibility is that PNA mice have a higher stress response to fasting and handling, leading to acutely elevated glucose. However, studies of steroid programing of the hypothalamicpituitary-adrenal axis indicate that adult stress responses are blunted by developmental androgen exposure (McCormick et al. 1998). DHT administered close to parturition as in our study could potentially change maternal nurturing

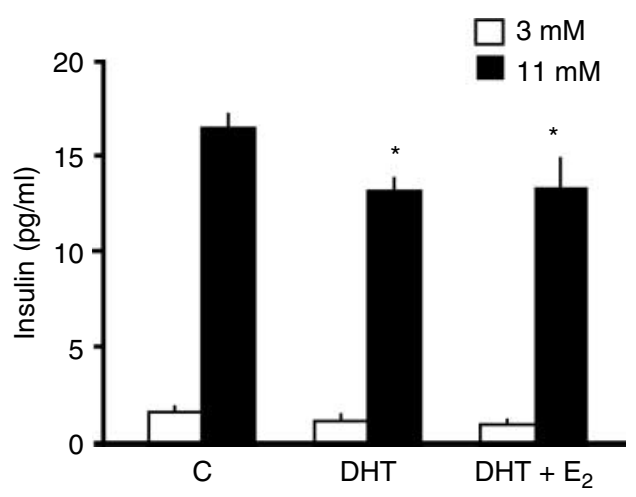

Figure 5 Steroids can act directly at the islet to alter insulin release in response to a glucose challenge. DHT or DHT in combination with estradiol $\left(D H T+E_{2}\right)$ impairs the release of insulin in response to a high-glucose challenge ( $n=12$ mice). ${ }^{*} P<0 \cdot 05$ versus control (C, ethanol vehicle) in $11 \mathrm{mM}$ glucose. 
behavior, which could also affect offspring stress responses (Francis et al. 1999).

Isolated islet studies were performed because the limited blood volume of mice makes sequential measurements of insulin secretion in vivo difficult to perform. $\left[\mathrm{Ca}^{2+}\right]_{\mathrm{i}}$ is closely coupled to insulin release in the $\beta$ cell, permitting $\left[\mathrm{Ca}^{2+}\right]_{\mathrm{i}}$ changes to be monitored as a surrogate for insulin secretion amid changing glucose concentrations (Jahanshahi et al. 2009). Islets are a heterogeneous tissue comprising $\alpha, \beta, \delta$, pancreatic polypeptide and $\varepsilon$ cells (Brissova \& Powers 2008), but $\beta$ cells comprise $65-80 \%$ of the islet mass; thus glucosestimulated $\left[\mathrm{Ca}^{2+}\right]_{\mathrm{i}}$ variations primarily reflect changes in this cell type. IGT in PNA mice did not progress to frank diabetes. Nevertheless, the observed defects in islet function are similar to the early islet dysfunction in type 2 diabetes mellitus (Jahanshahi et al. 2009). Hallmarks of pending islet failure include elevated basal calcium, loss of oscillatory activity, and failure to generate an appropriate rise in calcium (and thus insulin secretion) on high-glucose stimulation (Evans-Molina et al. 2009, Jahanshahi et al. 2009). Type 2 diabetes occurs in the context of peripheral insulin resistance, when pancreatic compensation to increase insulin production is no longer adequate (Kahn 2001). Thus, impaired pancreatic islet function in PNA mice may predispose them to develop type 2 diabetes in the presence of other risk factors, such as obesity. Similarly, women with PCOS have impaired $\beta$ cell function and are at increased risk for diabetes (Dunaif \& Finegood 1996, Legro et al. 1999).

An additional tissue-specific abnormality was identified, with PNA mice exhibiting increased visceral adipocyte size. Although enlarged adipocytes are often observed with increased fat mass, total fat pad mass was unchanged in PNA mice, suggesting that adipocyte number may be reduced. This idea is speculative; however, reports in the literature suggest that androgens can indeed alter adipocyte differentiation and size. DHT reduces omental adipocyte differentiation in tissue culture, and both DHT and testosterone inhibit differentiation of pluripotent cells into the adipogenic lineage (Singh et al. 2003, Blouin et al. 2009). Androgen receptor knockout mice have smaller adipocytes than wild-type controls, suggesting androgen receptor activation increases adipocyte size (Yeh et al. 2002). It must be emphasized that the change in adipocyte size observed in this study was small and did not result in associated changes in adipocyte insulin sensitivity (Lundgren et al. 2007) or changes in circulating levels of the majority of adipokines measured (Scherer \& Trujillo 2006, Skurk et al. 2007). In PNA mice, there was a strong trend for decreased adiponectin in the fed state, which is in agreement with reduced adiponectin levels in women with PCOS (Wickham et al. 2010). Further, leptin levels were not reduced by fasting in PNA mice, suggesting altered regulation of this hormone, which is permissive for fertility (Moschos et al. 2002). Differences in other adipokines, or in adipocyte insulin sensitivity, could appear under conditions of metabolic stress, such as diet-induced obesity. This is an interesting area for future studies.
Activational effects of androgens in islets were assessed because PNA mice previously exhibited elevated androgens (Sullivan \& Moenter 2004), a cardinal feature of PCOS. The androgen receptor ( $\mathrm{Li}$ et al. 2008) and synthesis enzyme cytochrome P450(17 $\alpha)$ (Ogishima et al. 2008) are expressed in $\beta$ cells, but their roles in this tissue are unclear. One study showed that micromolar concentrations of testosterone increase insulin transcription and secretion in the rat in vivo and in islets in vitro (Morimoto et al. 2001), but the possibility that effects were mediated by aromatization to $E_{2}$ or by nongenomic pathways were not examined. We found that overnight treatment with nanomolar concentrations of DHT impaired high-glucose-stimulated insulin release in islets from OVX mice. This effect was most likely genomic, as steroids were not present when insulin release was measured. $\mathrm{E}_{2}$ had no added effect. The reduction in glucose-stimulated insulin secretion following islet exposure to DHT in vitro was similar to the decrement in GSCa flux in islets from PNA mice. Since we did not observe elevated circulating androgens at 5 months of age when islets were isolated, islet dysfunction could not be attributed to activational effects of androgens. However, the effects of elevated androgen in adult life may be additive to those induced by prenatal androgen. PCOS is thought to involve elevated androgen prenatally and in adulthood, potentially generating a double insult on pancreatic function.

The absence of peripheral insulin resistance in PNA mice differs from previously published studies of PNA monkeys, sheep, and rats (Bruns et al. 2004, Recabarren et al. 2005, Demissie et al. 2008). In these models, insulin resistance was accompanied by an increase in total and/or visceral adiposity; the association between these conditions is well recognized (Kahn et al. 2006). PNA mice did not exhibit changes in body mass or composition, which may correlate with the absence of insulin resistance. An important distinction that may account for these differences is the androgen used. This study used DHT to examine primarily androgen receptor-mediated effects, whereas other studies used testosterone, which can be aromatized to $E_{2}$. This suggests a possible role of excess prenatal estrogen, or estrogen in combination with androgen, in programing obesity and peripheral insulin resistance. Prenatal exposure to estrogenic substances such as bisphenol A and diethylstilbestrol increases postnatal weight and adiposity (Miyawaki et al. 2007, Newbold et al. 2009). Estrogens may also potentiate the effects of androgens by upregulating the androgen receptor in specific tissues, including adipocytes and brain (McAbee \& Doncarlos 1999, Shao et al. 2007). Further, intrauterine growth restriction and its metabolic sequelae have been shown to be an effect of prenatal testosterone, but not DHT exposure (Steckler et al. 2005, Carlsen et al. 2006). In addition to the type of steroid treatment, other differences that may account for phenotypic discrepancies include the difference in species and variations in the timing of androgen administration. Sexual differentiation occurs during gestation in primates and sheep, whereas in rodents, it is incomplete at birth (MacLusky \& Naftolin 1981, Jackson et al. 2009). Thus, androgen 
exposure late in gestation in mice may be comparable to an early treatment in other species. Nevertheless, the developmental timeline in rats is similar to that in mice, and the treatment period in the PNA rat (days 16-19) overlaps ours. Hence, the steroid may be most important in establishing differences among models.

In this study, we have shown that prenatal androgens program long-term alterations in metabolic function in female mice. These findings have implications for gestational androgen exposure that originates from endogenous or exogenous sources. The absence of changes in circulating glucose, insulin, or the majority of adipokines assessed under fed conditions suggests that the previously observed reproductive dysfunction in this model was likely caused by androgen programing of the reproductive axis, and was not secondary to metabolic changes. Further, as the previously reported effects of prenatal androgenization to induce adiposity and insulin resistance were absent from PNA mice, it appears that metabolic programing by testosterone may be dependent on aromatization to $\mathrm{E}_{2}$ in addition to androgen receptor-mediated effects. The impairments observed in glucose tolerance and pancreatic islet function, as well as increased adipocyte size, may predispose PNA mice to develop diabetes in the presence of aggravating factors. This suggests a two-hit hypothesis, in which prenatal androgen programing sets the stage for metabolic dysfunction, and weight gain and insulin resistance secondary to prenatal estrogens or postnatal weight management drive the progression to diabetes.

\section{Declaration of interest}

The authors declare that there is no conflict of interest that could be perceived as prejudicing the impartiality of the research reported.

\section{Funding}

This research was supported by the Eunice Kennedy Shriver NICHD/NIH through cooperative agreement U54 HD28934 as part of the Specialized Cooperative Centers Program in Reproduction and Infertility Research, National Institute of Diabetes and Digestive and Kidney Disease DK063609, and National Institute of Neurological Disorders and Stroke National Research Service Award F31 NS062646 (AVR).

\section{Author contribution statement}

CSN performed islet calcium imaging and insulin secretion studies. SRK performed glucose uptake assays in adipocytes. All other experiments were designed and carried out by AVR under the supervision of her graduate advisor SMM. The manuscript was written by AVR.

\section{Acknowledgements}

We thank the following for their contributions to this paper: Animal Characterization Core and Cell and Islet Isolation Core at the UVA DERC (DK063609); Ligand Assay and Analysis Core and Histology Core at the UVA
Center for Research in Reproduction; Melissa Horal, Hongxia Chao, Toni Barbera, Runpei Wu, Jeff Carter, and Dan Haisenleder. We thank Debra Fisher for excellent technical assistance, and Justyna Pielecka, Jessica Kennett, and Jianli Sun for editorial comments on the manuscript.

\section{References}

Abbott DH, Barnett DK, Bruns CM \& Dumesic DA 2005 Androgen excess fetal programming of female reproduction: a developmental aetiology for polycystic ovary syndrome? Human Reproduction Update 11 357-374. (doi:10.1093/humupd/dmi013)

Amiel SA, Sherwin RS, Simonson DC, Lauritano AA \& Tamborlane WV 1986 Impaired insulin action in puberty. A contributing factor to poor glycemic control in adolescents with diabetes. New England Journal of Medicine 315 215-219. (doi:10.1056/NEJM198607243150402)

Arnold AP \& Breedlove SM 1985 Organizational and activational effects of sex steroids on brain and behavior: a reanalysis. Hormones and Behavior 19 469-498. (doi:10.1016/0018-506X(85)90042-X)

Blouin K, Veilleux A, Luu-The V \& Tchernof A 2009 Androgen metabolism in adipose tissue: recent advances. Molecular and Cellular Endocrinology 301 97-103. (doi:10.1016/j.mce.2008.10.035)

Bock G, Chittilapilly E, Basu R, Toffolo G, Cobelli C, Chandramouli V, Landau BR \& Rizza R 2007 Contribution of hepatic and extrahepatic insulin resistance to the pathogenesis of impaired fasting glucose: role of increased rates of gluconeogenesis. Diabetes 56 1703-1711. (doi:10.2337/ db06-1776)

Brill DS \& Moenter SM 2009 Androgen receptor antagonism and an insulin sensitizer block the advancement of vaginal opening by high-fat diet in mice. Biology of Reproduction 81 1093-1098. (doi:10.1095/biolreprod.109. 079301)

Brissova M \& Powers A 2008 Chapter 1. Architecture of Pancreatic Islets. Pancreatic Beta Cell in Health and Disease, pp 3-11. Eds Seino S \& Bell GI. Japan: Springer.

Bruns CM, Baum ST, Colman RJ, Eisner JR, Kemnitz JW, Weindruch R \& Abbott DH 2004 Insulin resistance and impaired insulin secretion in prenatally androgenized male rhesus monkeys. Journal of Clinical Endocrinology and Metabolism 89 6218-6223. (doi:10.1210/jc.2004-0918)

Cacho J, Sevillano J, de Castro J, Herrera E \& Ramos MP 2008 Validation of simple indexes to assess insulin sensitivity during pregnancy in Wistar and Sprague-Dawley rats. American Journal of Physiology. Endocrinology and Metabolism 295 E2169-E2176. (doi:10.1152/ajpendo.90207.2008)

Carlsen SM, Jacobsen G \& Romundstad P 2006 Maternal testosterone levels during pregnancy are associated with offspring size at birth. European Journal of Endocrinology 155 365-370. (doi:10.1530/eje.1.02200)

Carter JD, Dula SB, Corbin KL, Wu R \& Nunemaker CS 2009 A practical guide to rodent islet isolation and assessment. Biological Procedures Online $\mathbf{1 1}$ 3-31. (doi:10.1007/s12575-009-9021-0)

Chen J, Ahn K, Gee N, Ahmed M, Duleba A, Zhao L, Gee S, Hammock B \& Lasley B 2008 Triclocarban enhances testosterone action: a new type of endocrine disruptor? Endocrinology 149 1173-1179. (doi:10.1210/en. 2007-1057)

Deering TG, Ogihara T, Trace AP, Maier B \& Mirmira RG 2009 Methyltransferase Set7/9 maintains transcription and euchromatin structure at islet-enriched genes. Diabetes 58 185-193. (doi:10.2337/db08-1150)

Demissie M, Lazic M, Foecking EM, Aird F, Dunaif A \& Levine JE 2008 Transient prenatal androgen exposure produces metabolic syndrome in adult female rats. American Journal of Physiology. Endocrinology and Metabolism 295 E262-E268. (doi:10.1152/ajpendo.90208.2008)

Díaz-Sánchez V, Morimoto S, Morales A, Robles-Díaz G \& Cerbón M 1995 Androgen receptor in the rat pancreas: genetic expression and steroid regulation. Pancreas 11 241-245. (doi:10.1097/00006676-199510000-00005)

Dumesic DA, Abbott DH \& Padmanabhan V 2007 Polycystic ovary syndrome and its developmental origins. Reviews in Endocrine and Metabolic Disorders 8 127-141. (doi:10.1007/s11154-007-9046-0)

Dunaif A 1997 Insulin resistance and the polycystic ovary syndrome: mechanism and implications for pathogenesis. Endocrine Reviews $\mathbf{1 8}$ 774-800. (doi:10.1210/er.18.6.774) 
Dunaif A \& Finegood DT 1996 -Cell dysfunction independent of obesity and glucose intolerance in the polycystic ovary syndrome. Journal of Clinical Endocrinology and Metabolism 81 942-947. (doi:10.1210/jc. 81.3.942)

Evans-Molina C, Robbins RD, Kono T, Tersey SA, Vestermark GL, Nunemaker CS, Garmey JC, Deering TG, Keller SR, Maier B et al. 2009 Peroxisome proliferator-activated receptor gamma activation restores islet function in diabetic mice through reduction of endoplasmic reticulum stress and maintenance of euchromatin structure. Molecular and Cellular Biology 29 2053-2067. (doi:10.1128/MCB.01179-08)

Francis D, Diorio J, Liu D \& Meaney MJ 1999 Nongenomic transmission across generations of maternal behavior and stress responses in the rat. Science 286 1155-1158. (doi:10.1126/science.286.5442.1155)

Gore AC, Roberts JL \& Gibson MJ 1999 Mechanisms for the regulation of gonadotropin-releasing hormone gene expression in the developing mouse. Endocrinology 140 2280-2287. (doi:10.1210/en.140.5.2280)

Gray LE, Wilson VS, Stoker T, Lambright C, Furr J, Noriega N, Howdeshell K, Ankley GT \& Guillette L 2006 Adverse effects of environmental antiandrogens and androgens on reproductive development in mammals. International Journal of Andrology 29 96-104. (doi:10.1111/j.1365-2605. 2005.00636.x)

Handa R, Pak T, Kudwa A, Lund T \& Hinds L 2008 An alternate pathway for androgen regulation of brain function: activation of estrogen receptor $\beta$ by the metabolite of dihydrotestosterone, $5 \alpha$-androstane- $3 \beta, 17 \beta$-diol. Hormones and Behavior 53 741-752. (doi:10.1016/j.yhbeh.2007.09.012)

Henquin JC, Nenquin M, Stiernet P \& Ahren B 2006 In vivo and in vitro glucose-induced biphasic insulin secretion in the mouse: pattern and role of cytoplasmic $\mathrm{Ca}^{2+}$ and amplification signals in $\beta$-cells. Diabetes 55 441-451. (doi:10.2337/diabetes.55.02.06.db05-1051)

Hotchkiss AK, Furr J, Makynen EA, Ankley GT \& Gray LE 2007 In utero exposure to the environmental androgen trenbolone masculinizes female Sprague-Dawley rats. Toxicology Letters 174 31-41. (doi:10.1016/j.toxlet. 2007.08.008)

Jackson LM, Timmer KM \& Foster DL 2008 Sexual differentiation of the external genitalia and the timing of puberty in the presence of an antiandrogen in sheep. Endocrinology 149 4200-4208. (doi:10.1210/en. 2007-1382)

Jackson LM, Timmer KM \& Foster DL 2009 Organizational actions of postnatal estradiol in female sheep treated prenatally with testosterone: programming of prepubertal neuroendocrine function and the onset of puberty. Endocrinology 150 2317-2324. (doi:10.1210/en.2008-1307)

Jahanshahi P, Wu R, Carter JD \& Nunemaker CS 2009 Evidence of diminished glucose stimulation and endoplasmic reticulum function in nonoscillatory pancreatic islets. Endocrinology 150 607-615. (doi:10.1210/ en.2008-0773)

Kahn SE 2001 Clinical review 135: the importance of $\beta$-cell failure in the development and progression of type 2 diabetes. Journal of Clinical Endocrinology and Metabolism 86 4047-4058. (doi:10.1210/jc.86.9.4047)

Kahn SE, Hull RL \& Utzschneider KM 2006 Mechanisms linking obesity to insulin resistance and type 2 diabetes. Nature 444 840-846. (doi:10.1038/ nature 05482)

Legro RS, Driscoll D, Strauss JF III, Fox J \& Dunaif A 1998 Evidence for a genetic basis for hyperandrogenemia in polycystic ovary syndrome. PNAS 95 14956-14960. (doi:10.1073/pnas.95.25.14956)

Legro RS, Kunselman AR, Dodson WC \& Dunaif A 1999 Prevalence and predictors of risk for type 2 diabetes mellitus and impaired glucose tolerance in polycystic ovary syndrome: a prospective, controlled study in 254 affected women. Journal of Clinical Endocrinology and Metabolism 84 165-169. (doi:10. $1210 /$ jc.84.1.165)

Li RJ, Qiu SD, Wang HX, Tian H, Wang LR \& Huo YW 2008 Androgen receptor: a new player associated with apoptosis and proliferation of pancreatic $\beta$-cell in type 1 diabetes mellitus. Apoptosis 13 959-971. (doi:10. 1007/s10495-008-0230-9)

Liu SCH, Wang Q, Lienhard GE \& Keller SR 1999 Insulin receptor substrate 3 is not essential for growth or glucose homeostasis. Journal of Biological Chemistry 275 18093-18099. (doi:10.1074/jbc.274.25.18093)
Lundgren M, Svensson M, Lindmark S, Rensrom F, Ruge T \& Eriksson JW 2007 Fat cell enlargement is an independent marker of insulin resistance and 'hyperleptinaemia'. Diabetologia 50 625-633. (doi:10.1007/s00125-0060572-1)

MacLusky NJ \& Naftolin F 1981 Sexual differentiation of the central nervous system. Science 211 1294-1302. (doi:10.1126/science.6163211)

Mather K 2009 Surrogate measures of insulin resistance: of rats, mice, and men. American Journal of Physiology. Endocrinology and Metabolism 296 E398E399. (doi:10.1152/ajpendo.90889.2008)

McAbee MD \& Doncarlos LL 1999 Estrogen, but not androgens, regulates androgen receptor messenger ribonucleic acid expression in the developing male rat forebrain. Endocrinology 140 3674-3681. (doi:10.1210/ en.140.8.3674)

McCartney CR, Prendergast KA, Chhabra S, Eagleson CA, Yoo R, Chang RJ, Foster CM \& Marshall JC 2006 The association of obesity and hyperandrogenemia during the pubertal transition in girls: obesity as a potential factor in the genesis of postpubertal hyperandrogenism. Journal of Clinical Endocrinology and Metabolism 91 1714-1722. (doi:10.1210/ jc.2005-1852)

McCormick CM, Furey BF, Child M, Sawyer MJ \& Donohue SM 1998 Neonatal sex hormones have 'organizational' effects on the hypothalamicpituitary-adrenal axis of male rats. Brain Research. Developmental Brain Research 105 295-307. (doi:10.1016/S0165-3806(97)00155-7)

Miyawaki J, Sakayama K, Kato H, Yamamoto H \& Masuno H 2007 Perinatal and postnatal exposure to bisphenol a increases adipose tissue mass and serum cholesterol level in mice. Journal of Atherosclerosis and Thrombosis $\mathbf{1 4}$ 245-252.

Morimoto S, Fernandez-Mejia C, Romero-Navarro G, Morales-Peza N \& Díaz-Sánchez V 2001 Testosterone effect on insulin content, messenger ribonucleic acid levels, promoter activity, and secretion in the rat. Endocrinology 142 1442-1447. (doi:10.1210/en.142.4.1442)

Moschos S, Chan JL \& Mantzoros CS 2002 Leptin and reproduction: a review. Fertility and Sterility 77 433-444. (doi:10.1016/S0015-0282(01)03010-2)

Newbold RR, Padilla-Banks E \& Jefferson WN 2009 Environmental estrogens and obesity. Molecular and Cellular Endocrinology 304 84-89. (doi:10.1016/j.mce.2009.02.024)

Ogishima T, Mitani F \& Suematsu M 2008 Cytochrome P-450(17 $\alpha$ ) in $\beta$-cells of rat pancreas and its local steroidogenesis. Journal of Steroid Biochemistry and Molecular Biology 111 80-86. (doi:10.1016/j.jsbmb.2008.04.008)

Quigley CA 2002 Editorial: the postnatal gonadotropin and sex steroid surge insights from the androgen insensitivity syndrome. Journal of Clinical Endocrinology and Metabolism 87 24-28. (doi:10.1210/jc.87.1.24)

Rosenbaum D, Haber RS \& Dunaif A 1993 Insulin resistance in polycystic ovary syndrome: decreased expression of Glut-4 glucose transporters in adipocytes. American Journal of Physiology-Endocrinology and Metabolism 264 E197-E202.

Recabarren SE, Padmanabhan V, Codner E, Lobos A, Durán C, Vidal M, Foster DL \& Sir-Petermann T 2005 Postnatal developmental consequences of altered insulin sensitivity in female sheep treated prenatally with testosterone. American Journal of Physiology. Endocrinology and Metabolism 289 E801-E806. (doi:10.1152/ajpendo.00107.2005)

Sam S \& Dunaif A 2003 Polycystic ovary syndrome: syndrome XX? Trends in Endocrinology and Metabolism 14 365-370. (doi:10.1016/j.tem.2003.08.002)

Scherer PE \& Trujillo ME 2006 Adipose tissue-derived factors: impact on health and disease. Endocrine Reviews 27 762-778. (doi:10.1210/er.20060033)

Shao RLK, Weijdegård B, Egecioglu E, Fernandez-Rodriguez J, Zhang FP, Thurin-Kjellberg A, Bergh C \& Billig H 2007 Estrogen-induced upregulation of AR expression and enhancement of AR nuclear translocation in mouse fallopian tubes in vivo. American Journal of Physiology. Endocrinology and Metabolism 292 E604-E614. (doi:10.1152/ajpendo. 00350.2006)

Singh R, Artaza J, Taylor W, Gonzalez-Cadavid N \& Bhasin S 2003 Androgens stimulate myogenic differentiation and inhibit adipogenesis in C3H 10T1/2 pluripotent cells through an androgen receptor-mediated pathway. Endocrinology 144 5081-5088. (doi:10.1210/en.2003-0741)

Sir-Petermann T, Maliqueo M, Angel B, Lara HE, Perez-Bravo F \& Recabarren SE 2002 Maternal serum androgens in pregnant women with 
polycystic ovarian syndrome: possible implications in prenatal androgenization. Human Reproduction 17 2573-2579. (doi:10.1093/humrep/17.10. 2573)

Sir-Petermann T, Codner E, Perez V, Echiburu B, Maliqueo M, Ladron de Guevara A, Preisler J, Crisosto N, Sanchez F, Cassorla F et al. 2009 Metabolic and reproductive features before and during puberty in daughters of women with polycystic ovary syndrome. Journal of Clinical Endocrinology and Metabolism 94 1923-1930. (doi:10.1210/jc.2008-2836)

Skurk T, Alberti-Huber C, Herder C \& Hauner H 2007 Relationship between adipocyte size and adipokine expression and secretion. Journal of Clinical Endocrinology and Metabolism 92 1023-1033. (doi:10.1210/jc.2006-1055)

Steckler T, Wang J, Bartol FF, Roy SK \& Padmanabhan V 2005 Fetal programming: prenatal testosterone treatment causes intrauterine growth retardation, reduces ovarian reserve and increases ovarian follicular recruitment. Endocrinology 146 3185-3193. (doi:10.1210/en.2004-1444)

Sullivan SD \& Moenter SM 2004 Prenatal androgens alter GABAergic drive to gonadotropin-releasing hormone neurons: implications for a common fertility disorder. PNAS 101 7129-7134. (doi:10.1073/pnas.0308058101)

Tapanainen J, Kellokumpu-Lehtinen P, Pelliniemi L \& Huhtaniemi I 1981 Age-related changes in endogenous steroids of human fetal testis during early and midpregnancy. Journal of Clinical Endocrinology and Metabolism $\mathbf{5 2}$ 98-102. (doi:10.1210/jcem-52-1-98)
Wickham EP III, Cheang KI, Clore JN, Baillargeon JP \& Nestler JE 2010 Total and high-molecular weight adiponectin in women with the polycystic ovary syndrome. Metabolism (In Press). (doi:10.1016/j.metabol.2010.02.019)

Winborn WB, Sheridan PJ \& McGill HCJ 1987 Sex steroid receptors in the stomach, liver, pancreas, and gastrointestinal tract of the baboon. Gastroenterology 9223.

Wood RI, Ebling FJ, I'Anson H, Bucholtz DC, Yellon SM \& Foster DL 1991 Prenatal androgens time neuroendocrine sexual maturation. Endocrinology 128 2457-2468. (doi:10.1210/endo-128-5-2457)

Yeh S, Tsai MY, Xu Q, Mu XM, Lardy H, Huang KE, Lin H, Yeh SD, Altuwaijri S, Zhou X et al. 2002 Generation and characterization of androgen receptor knockout (ARKO) mice: an in vivo model for the study of androgen functions in selective tissues. PNAS 99 13498-13503. (doi:10. 1073/pnas.212474399)

\section{Received in final form 11 August 2010 \\ Accepted 16 August 2010 \\ Made available online as an Accepted Preprint 16 August 2010}

